\title{
Effects of aeration on matrix temperature by infrared thermal imager and computational fluid dynamics during sludge bio-drying
}

\author{
Dawei Yu $^{\text {a, b }}$, Min Yang a, b, Lu Qi ${ }^{\text {a, b }}{ }^{\text {, Mengmeng Liu }}{ }^{\text {a, b }}$, Yawei Wang ${ }^{\text {a, b }}$, \\ Yuansong Wei ${ }^{\text {a, b, * }}$ \\ a State Key Joint Laboratory of Environmental Simulation and Pollution Control, Research Center for Eco-Environmental Sciences, Chinese Academy of \\ Sciences, Beijing 100085, China \\ ${ }^{\mathrm{b}}$ University of Chinese Academy of Sciences, Beijing 100049, China
}

\section{A R T I C L E I N F O}

\section{Article history:}

Received 21 January 2017

Received in revised form 1 June 2017

Accepted 2 June 2017

Available online 4 June 2017

\section{Keywords:}

Bio-drying

Computational fluid dynamics

Infrared thermal imager

Aeration

Matrix temperature

Excess sludge

\begin{abstract}
A B S T R A C T
The effect of aeration on the pile matrix temperature was investigated using thermocouples and Infrared Thermal Imager (IRI) for temperature sensing, and Computational Fluid Dynamics (CFD) for modelling of temperature variation during aeration in a full-scale sludge biodrying plant. With aeration saving of $20 \%$, the improved strategy speeded up biodrying from 21 days to 14 days, while achieving similar drying effect. A persistent thermocouple recorded the one-dimensional (1D) total temperature variation of all aeration strategies. The IRI captured the rapid two-dimensional (2D) pile temperature dropped from $72.5{ }^{\circ} \mathrm{C}$ to $30.3^{\circ} \mathrm{C}$ during 6 min of aeration, which mechanism suggested as the latent heat of moisture evaporation and sensible heat of air exchange. The CFD three-dimensional (3D) CFD results highlight the importance of latent heat rather than sensible heat. Therefore, the pile temperature drop inferred is $\Delta \mathrm{T}=5.38^{\circ} \mathrm{C}$ theoretically and $\Delta \mathrm{T}=5.17 \pm 4.56^{\circ} \mathrm{C}$ practically, per unit of $\mathrm{MC}$ removed. These findings also emphasize the possibility of a pile temperature valley, due to excessive aeration under unsaturated vapour conditions. Surface temperature monitored by IRI coupled with 3D temperature simulated by CFD rapidly gives a clear matrix temperature evolution, empowering biodrying by more accurate temperature and aeration.
\end{abstract}

() 2017 Elsevier Ltd. All rights reserved.

\section{Introduction}

Due to its reduction of high moisture content (MC) using biogenerated internal heat instead of external heat, bio-drying is regarded as a green biofuel pathway from biomass, for example, in the drying of sewage sludge (Cai et al., 2016). A capacity goal of increasing the treatment rate of sewage sludge from $20 \%$ to $90 \%$ was set by the Action Plan for Water Pollution Prevention and Control of China (State Council of China, 2015). Therefore, sludge bio-drying plants are rapidly being built in China.

Derived from composting, the aim of bio-drying is to quickly remove MC removal and it shares a similar thermodynamic process. According to the bio-generated heat, composting can be

\footnotetext{
* Corresponding author. Department of Water Pollution Control Technology, State Joint Laboratory of Environmental Simulation and Pollution Control, Research Center for Eco-Environmental Science, Chinese Academy of Sciences, Beijing 100085, China.

E-mail address: yswei@rcees.ac.cn (Y. Wei).
}

divided into two distinct thermodynamic regions as follows: one in which the energy supply is sufficient for both biodegradation and drying, and another in which energy is sufficient for biodegradation with only limited drying (Haug, 1993). Aeration is a key parameter for manipulating the thermodynamic regions (Cai et al., 2013). By sustaining the first thermodynamic region with proper aeration, bio-drying can keep a higher temperature and better reduce MC, thereby making it more efficient. Much research has therefore been done related to aeration. The results showed that the bio-generated heat and pile temperature during sludge bio-drying were affected by aeration, factors of which include forced air volume, aeration strategy and air flow rate (Cai et al., 2013; Villegas and Huilinir, 2014; Zhao et al., 2010). Several researchers supposed that the outlet air temperature is equal to that of the matrix temperature (He et al., 2013; Yang et al., 2014), but it is not necessarily equal due to non-equilibrium conditions, for example, high air flow rate (AFR)(Huilinir and Villegas, 2015) or low pile height (Tom et al., 2016). The spatial matrix temperatures are not necessarily the same due to the different heat transfer rates of substrates (Zhao 
et al., 2011) and to the heat insulation of free air space (FAS)(Cai et al., 2013). To date, only a few researchers have presented values of outlet air temperatures while working with these values using AFR (Frei et al., 2004; He et al., 2013; Huilinir and Villegas, 2015). Therefore, establishing the effect of aeration on matrix temperature was one of the goals of this work.

The temperature monitor is a major parameter of aeration control systems for biodrying and composting. It is well known that the pile temperature usually goes through four typical stages: the pile temperature increasing stage, thermophilic stage, the second temperature increasing stage and cooling stage (Cai et al., 2013; Zhao et al., 2011). Pile temperature is mostly determined using a thermometer with a thermocouple, which is accurate but timeconsuming because measurement is limited by the heat conduction speed of the probe (Ramirez et al., 2012). The pile temperature changes are rapid during aeration aimed at MC removal, because this involves rapid phase transformation in which latent heat accounts for $70 \%-80 \%$ of total energy output (Haug, 1993). The matrix temperature of the pile will vary spatio-temporally, especially during aeration. However, the thermocouple can be only installed on the wall rather than inserted into the pile due to the agitator in a horizontal agitated solid bed (HASB) (Fig. A.1), failed to represent the spatial variation of pile temperature. Due to these shortcomings of the thermocouples used in monitoring the spatio-temporal pile temperature, excess aeration is inescapable due to the rapid changes in pile temperature during bio-drying, thus causes more energy consumption and low efficiency of bio-drying. Excess aeration leads to rapid dropping of the pile temperature, overly cool thermodynamic condition and early termination of the first three stages (Shen et al., 2011). Typically, aeration energy consumption varies from $26.9 \mathrm{kWh} \mathrm{t}^{-1}$ to $53.6 \mathrm{kWh} \mathrm{t}^{-1}$ for sludge bio-drying (Wei et al., 2001), which could be further decreased by optimizing the aeration strategy. These results in inefficient $\mathrm{MC}$ removal for sludge bio-drying; therefore, highly responsive monitoring of the matrix temperature is badly needed for pile temperature investigation in sludge bio-drying.

Along with a bio-generated heat source like that of composting, bio-drying also shares moisture removal by mechanical aeration drying, as used for bulk grain and industrial granules. Computational fluid dynamics (CFD) is a well-established tool that has proven its effectiveness in the design of many drying reactors used in thermodynamic and hydrodynamic industries (Norton et al., 2007). Modern CFD codes and rapidly expanding computing capabilities make it feasible to do flow modelling of full-scale facilities (Bendjebbas et al., 2016). The CFD simulation could speed up optimization of full scale biodrying, whereas equivalent experiments would cost lots of money and time. Modern CFD codes for simulating air flow in porous media have a broad range of applications, from corn seed drying to crop production systems (Norton et al., 2007). These CFD applications share flow characteristics similar to those of sludge composting, according to previous investigations in aeration pressure (Guardo et al., 2004; Yan et al., 2008). The bio-generated heat source and its self-heating impacts on pile temperature has been modelled with an original finitevolume computer code, written in Fortran (Zambra and Moraga, 2013; Zambra et al., 2011). With equilibrium assumption (Zambra et al., 2011), the pile temperature variation during aeration remains ambiguous which is essential in full scale plants. The turbulence model applied in this work was the $k-\varepsilon$ turbulence model. Convection, conduction and radiation heat transfer among the porous media were conjugated with air flow. The simulation results of pile matrix temperature were verified and showed greater linkage with velocity fields than with mixing parameters (Guardo et al., 2004). For the mass-transfer as MC lost during drying, several approaches have been proposed for porous materials which could be used for heterogeneous and hygroscopic materials ( $\mathrm{He}$ et al., 2013; Huilinir and Villegas, 2015; Villegas and Huilinir, 2014). However, it remains a great challenge for building a universal model of MC removal rates because of the multitude of variations in internal and external conditions that occur during the bio-drying process (Zhao et al., 2010).

Therefore, this work focus on the effect of aeration on matrix temperature of biodrying pile, where matrix temperature spatiotemporal variated was investigated using a novel Infrared Thermal Imager (IRI) and Computational Fluid Dynamics (CFD). Meanwhile, the thermodynamic mechanism of the pile temperature valley between the thermophilic stage and second temperature increasing stage was discussed, and the temperature change per unit of MC removal inferred.

\section{Material and methods}

\subsection{Plant configurations and aeration strategies}

The full-scale sludge bio-drying plant in this study has the designed capacity for treating $1000 \mathrm{t} \mathrm{d}^{-1}$ of excess sludge to reduce MC from $80 \%$ to $40 \%$. It is the largest sludge bio-drying plant in China, and is located in Shenyang (Liaoning Province, China). The plant has 96 parallel tunnels in total, and the size of each tunnel is $96 \mathrm{~m} \times 3 \mathrm{~m} \times 2.5 \mathrm{~m}$ (Length $\times$ Width $\times$ Height), including a premix area with the length of $6 \mathrm{~m}$ as shown in Fig. 1. The tunnel is a horizontal agitated solid bed (HASB, Fig. A.1c) reactor with forced aeration, mechanical turning and in-situ temperature sensing (Fig. A.1). The forced aeration was divided into six different sections

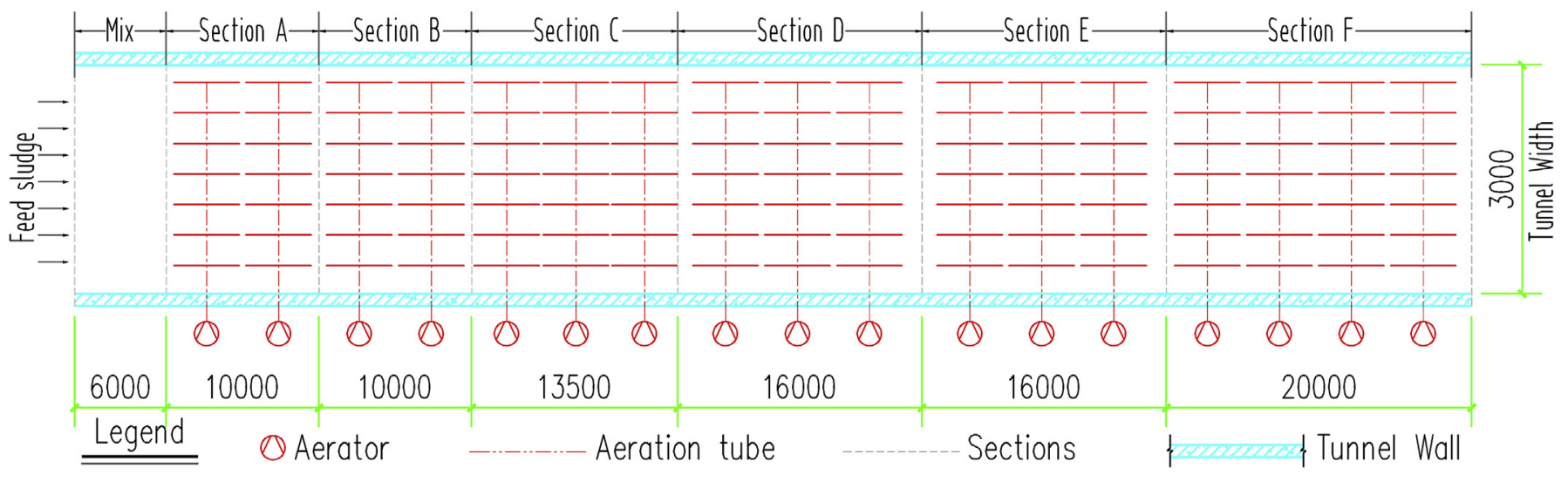

Fig. 1. Schemes of the sludge bio-drying plant (units: mm). 
(A, B, C, D, E, F) as shown in Fig. 1. The turning equipment (IPS, Siemens AG, Fig. A.1b) was capable of moving forward $4 \mathrm{~m}$ along the tunnel with each turn. The environmental temperature of the piles was stabilized by adjusting the exchange of fresh (outside) air, because all the piles were covered to collect the outlet air. All the outlet air was treated by bio-filtration for odour control.

Three aeration strategies (Table 1) were applied for three parallel tunnels to investigate effects of aeration on the evolution of the spatio-temporal pile temperature during sludge bio-drying. The Pile 0 was used as the control, in which the aeration strategy was the same as that current used in operating the Shenyang Zhenxing Sludge Bio-drying Plant with a bio-drying period of 21 days. The Pile 1 and Pile 2 were designed as experiments, in which different aeration strategies, including aeration time and turning frequency, were applied according to the functions of oxygen demand, pile temperature maintenance and moisture evaporation for speeding MC removal during four different periods (Table 1). In Section A, B and $C$ of Pile 1 , aeration was used to prolong the thermophilic stage by setting the initial pile temperature at less than $40^{\circ} \mathrm{C}$, because lower pile temperature limits the biodegrading of substrates. In Section D, E and F of Pile 1, aeration time was decreased to slow down the decrease of pile temperature, which reduce the thermal energy taken away with the air. In section A of Pile 2, air was supplied to prolong the initial thermophilic stage. Then, aeration time was slightly decreased to maintain a more stable pile temperature in Section B, C, D and E. In section F of Pile 2, air was supplied to further decrease moisture by enhancing evaporation. The turning difference between Pile 1 and Pile 2 was the mechanical turning frequency because the periods of Pile I and Pile II were set at 21 days and 14 days, respectively.

\subsection{Sludge characteristics}

The raw dewatered sludge was mostly from municipal wastewater treatment plants, which sludge contained approximately $80 \%$ MC, and a small amount of the sludge was from industrial wastewater treatment plants. Before the bio-drying process, the dewatered sludge was mixed with rice hull and returned sludge biodrying product in the premix area of each tunnel, to adjust the MC to $\sim 60 \%$ and increase porosity (Table 1 ).

The thermal and dynamic characteristics of the sewage sludge were changing along with the bio-drying process and operating conditions, so these characteristics were formula calculated based on field test results. The calculated results were also checked against a report published in China, because Chinese sludge contains less organic matter and caloricity than those of Europe and America due to different urban wastewater collection systems and life styles (General Office of the State Council, 2012).

The sludge density was calculated as the moisture weighted average of dry sludge $\left(2600 \mathrm{~kg} \mathrm{~m}^{-3}\right)$ and water $\left(1000 \mathrm{~kg} \mathrm{~m}^{-3}\right)$ by Eq. (1), where $\theta$ is the MC (\%) of sludge, calculated as fraction. All the parameters were listed as Table A.1.

$\rho_{s}=2600(1-\theta)+1000 \theta$

The specific heat capacity was calculated as the moisture weighted average of dry sludge $\left(1300 \mathrm{j} \mathrm{kg}^{-1} \mathrm{~K}^{-1}\right)$ and water (4187 $\mathrm{j} \mathrm{kg}^{-1} \mathrm{~K}^{-1}$ ) by Eq. (2).

$c_{p}=1300(1-\theta)+4187 \theta$

The thermal conductivity of the sludge was calculated using Eq. (3) according to the MC of the sludge. Because the pile temperature ranged widely during aeration of sludge bio-drying, the thermal conductivity was also determined using a piecewise-line function of pile temperature (Wang et al., 2015).

$k_{n}=0.0703 e^{2.0238 \times \theta}$

The pile porosity is determined as free air space (FAS) of the pile, which is calculated according to the method proposed by United States Composting Council (US Composting Council, 2002). The parameter $\gamma_{s}$ was defined as the bulk density of sludge (Villegas and Huilinir, 2014).

$\mathrm{FAS}=1-\frac{\gamma_{S} \times(1-\theta)}{\rho_{S}}-\frac{\gamma_{S} \times \theta}{1000}$

The heat transfer coefficient for the interface of air and piles was $220 \mathrm{~W} \mathrm{~m}^{-2} \mathrm{~K}^{-1}$, and the interfacial area density $A_{f s}$ was determined by the specific surface area and bulk density $\gamma_{\mathrm{s}}$ (Huang, 2015).

\subsection{Pile temperature at different depths measured by thermocouple}

One-dimensional (1D) temperature was recorded with thermocouple at all sample points. To obtain a representative pile temperature distribution and solid sample, the horizontal area of each section was diagonally divided into four parts, and five sampling points were chosen on the diagonals. Surface and interior pile temperatures of center sample point were monitored using

Table 1

Operation conditions for the sludge bio-drying plant.

\begin{tabular}{|c|c|c|c|c|}
\hline \multicolumn{2}{|c|}{ Operation Conditions } & Pile 0 (Control) & Pile 1 & Pile 2 \\
\hline \multicolumn{2}{|c|}{ Turning Frequency (times/day) } & 1 & 1 & 2 in 1 st week, 1 in 2 nd week \\
\hline \multicolumn{2}{|c|}{ Total Solid Retention Time (days) } & 22 & 22 & 14 \\
\hline \multirow[t]{4}{*}{ Feed } & Quantification & Shovel Loader & & \\
\hline & Mixing & $\begin{array}{l}\text { BACKHUS Lane Turner, } \\
\text { BACKHUS Gmbh, German }\end{array}$ & & \\
\hline & Mixing ratio ${ }^{a}$ & $1: 0.62: 0.28$ & $1: 0.62: 0.28$ & $1: 0.62: 0.28$ \\
\hline & Weight (for each pile) & $\sim 24.6 \mathrm{t}$ & & \\
\hline Pile Size & $\mathrm{L} \times \mathrm{B} \times \mathrm{H}(\mathrm{m})$ & $4 \times 3 \times 2$ & & \\
\hline Aeration Strategy & Section A (SRT/days) & TC, C: $4, \mathrm{~T}: 45(2.50)$ & TC, C: $10, \mathrm{~T}: 40(2.50)$ & TC, C: $6, \mathrm{~T}: 45$ (1.125) \\
\hline $\mathrm{C}^{\mathrm{b}}:\left(\mathrm{min} \cdot \mathrm{h}^{-1}\right)$ & Section B (SRT/days) & TC, C: $8, T: 55(2.50)$ & TC, C: $15, \mathrm{~T}: 40(2.50)$ & TC, C: $6, \mathrm{~T}: 55$ (1.125) \\
\hline \multirow[t]{4}{*}{$\mathrm{T}^{\mathrm{c}}:\left({ }^{\circ} \mathrm{C}\right)$} & Section C (SRT/days) & C: $15(3.50)$ & TC, C: $10, \mathrm{~T}: 40(3.50)$ & C: $12(1.68)$ \\
\hline & Section D (SRT/days) & C: $17(4.00)$ & $\mathrm{TC}, \mathrm{C}: 10, \mathrm{~T}: 35(4.00)$ & C: $14(2.00)$ \\
\hline & Section E (SRT/days) & C: $20(4.00)$ & TC, C: 5, T: $35(4.00)$ & C: $14(2.37)$ \\
\hline & Section F (SRT/days) & C: $30(5.00)$ & TC, C: $5, \mathrm{~T}: 35(5.00)$ & C: $30(5.00)$ \\
\hline
\end{tabular}

${ }^{a}$ The ratio is weight ratio of raw sludge: back-mixed sludge: husk, respectively.

$\mathrm{b}$ The $\mathrm{C}$ mode refers to that aerators of the section were periodically started for $\mathrm{C}$ minute per hour.

c The $\mathrm{T}$ mode refers to that aerators were automatically started when monitor temperature over ${ }^{\circ} \mathrm{C}$, where the aeration sustained time was given in the brackets. Sensor was install on the tunnel, monitoring the pile surface temperature. 
thermocouples (KT B-8A, Kaitai Inc., China) during each point solids sampling, equipped with Pt100 electrodes (Huilinir and Villegas, 2014). To compare surface and interior pile temperature, two different depths of the pile were measured at $0.5 \mathrm{~m}$ and $1.5 \mathrm{~m}$, respectively. The depth of $0.5 \mathrm{~m}$ selected depended on the heat balance needs of the thermocouple, as a representation of the surface temperature. The depth of $1.5 \mathrm{~m}$ is at the mid-depth of the pile. The pile temperature was recorded when the thermometer reading was stable for $60 \mathrm{~s}$, after the thermocouples were inserted to the sampling points. Then the surface and interior pile temperature were recorded in each section.

\subsection{Pile temperature on surface measured by Infrared Thermal Imager (ITI)}

The infrared thermal imager is based on infrared radiation energy of the detected objects surface to determine their temperature, which is captured as two-dimensional (2D) temperature by the infrared camera as thermograms in IS2 format (Zhan et al., 2012). Pile temperature measurements of the pile surfaces were carried out using an infrared thermal imager (ITI) (Fluke Ti $110 \mathrm{~Hz}$ Thermal Imager, Fluke Corporation, USA) equipped with a 2megapixel industrial-grade infrared camera. The spectral band, refresh rate and temperature measurement range of the infrared camera were $7.5-14 \mu \mathrm{m}, 9 \mathrm{~Hz}$ and $-20{ }^{\circ} \mathrm{C}-250{ }^{\circ} \mathrm{C} \pm 2 \%$, respectively. Prior to IRI capture, the infrared camera was calibrated for the pile temperature test. Thermograms of each section were systematically captured at a distance of $1.2 \mathrm{~m}$ over the sample region of the piles with incidence of 90 . The thermograms were captured before sample collection at the same places. All the temperature records were obtained from the same location and time as corresponding samples. For each measurement, thermograms were recorded, downloaded, and visualized with SmartView V2.1 (Fluke Thermography, Fluke Corporation, USA) (Marins et al., 2014).

The thermograms in each pile were taken in parallel performed before each pile was turned on Day 1, 2, 3, 4, 5, 7, 9, 11, 14, 16, 19 and 21. Because each was turned every day, the piles were considered to have been homogeneous. To obtain a representative spatial temperature distribution, the horizontal central surface of each section (Fig. A.2) was captured using the thermal imager. Prior to the capture of the pile temperature, the surface sludge $(40-50 \mathrm{~cm})$ was scraped away to obtain a surface temperature thermogram not influenced by the ambient temperature. The captured IRI thermograms were also applied for validation of CFD simulation results, which difference was compared by average temperature in nine regions.

\subsection{Analysis}

After the pile temperature was measured, the surface and interior solids samples (100-200 g each) were collected at a pile depth of $45-55 \mathrm{~cm}$ and $1450-1550 \mathrm{~cm}$ (Fig. A.2), respectively. Each type of samples was mixed together to acquire a representative sample (100 g) using the quartering method. Each solids sample was divided into two parts, one part sample was used for analysis of physical and chemical parameters, and the other part sample was stored at $-20{ }^{\circ} \mathrm{C}$ for further analysis.

The MC (\%) was measured by drying the solid sample in an oven at $105{ }^{\circ} \mathrm{C}$ until a constant weight was achieved; the remaining weight fraction $(1-\mathrm{MC})$ was regarded as total solids (TS, \%). The volatile solids (VS, \%) content was analysed by heating the dried sample at $600{ }^{\circ} \mathrm{C}$ for $6 \mathrm{~h}$ in an electrical muffle furnace. All tests were conducted in duplicate.

\subsection{CFD thermal model}

The pile was discretized with an unstructured finite volumes mesh. The hexahedral grids with a total number of 5,290,000 and $4,360,000$ and 3,270,000 computational nodes were used. The air flow and heat exchanging is physically modelled by the conservation of mass, momentum and energy. The porous media model and $\mathrm{k}-\varepsilon$ model was respectively applied for modelling of resistance and turbulence, when air flow through the pile. Meanwhile, the nonEquilibrium Thermal Model was also applied for modelling of heat exchanges between air and pile. These models joint as an equation set, was discretized and solved numerically using the finite volume method in a CFD software. The applied CFD software is Academic Research ANSYS-Fluent code (V15.0, ANSYS Inc., USA), which has been widely used in the simulation of similar systems, for example aeration system of agriculture industry (Norton et al., 2007).

In this work, the porous media model was employed to investigate the three-dimensional (3D) thermal transfer of gas-solid phase in the sludge bio-drying plant because of the obvious computational advantages of this model at the two-phase thermal transfer of porous media. In this model, gas was considered a continuous fluid cell, and sludge was considered a porous media solid cell. Gas and solid cells were both treated as interpenetrating and interacting with each other everywhere in the computational domain. Air was considered incompressible. The governing equations of mass, momentum and energy balance were solved for air and can be written as follows.

\subsubsection{Continuity equations}

$\frac{\partial \rho}{\partial \mathrm{t}}+\nabla \cdot(\rho \vec{v})=S_{m}$

where $\rho, t$ and $\vec{v}$ are the density, time and velocity vector of incompressible air, respectively. The mass source term $S_{m}$ on the right side of Eq. (5) is zero because the interphase mass transfer is not taken into consideration in this model.

\subsubsection{Momentum equations}

$\frac{\partial}{\partial \mathrm{t}}(\rho \vec{v})+\nabla \cdot(\rho \vec{v} \vec{v})=-\nabla \cdot p+\nabla \cdot\left(\mu\left(\nabla \vec{v}+\nabla \vec{v}^{T}\right)\right)+(\rho \vec{g} \vec{v})+\vec{F}$

where $p, \mu$ and $\vec{g}$ are the static pressure, the viscosity and the gravitational acceleration vector, respectively. The $\vec{F}$ on the right side of Eq. (6) is the external body force dependent on porous media model which is defined by section 2.3.5 Non-Equilibrium Thermal Model.

\subsubsection{Energy equations}

$$
\begin{aligned}
\frac{\partial}{\partial \mathrm{t}}[\rho E]+\nabla \cdot(\vec{v}(\rho E+p))= & \nabla \cdot\left[k_{e f f} \nabla \mathrm{T}-\vec{J}+\left(\overline{\bar{\tau}}_{e f f} \cdot \vec{v}\right)\right]+S_{h} \\
& +h_{a s} A_{a s}\left(T_{s}-T_{a}\right)
\end{aligned}
$$

In Eq. (7),

$$
E=\left(\int_{T_{\text {ref }}}^{T} c_{p} d T+\frac{v^{2}}{2}\right)
$$

where $T$ is temperature $(\mathrm{t}+273.15 \mathrm{~K})$ and $T_{\text {ref }}$ is $298.15 \mathrm{~K}$, which is 
defined in the Fluent pressure-based solver. The $c_{p}, k_{\text {eff }}$ and $\vec{J}$ are specific heat capacity, thermal conductivity and diffusion flux, respectively. The first three terms on the right-hand side of Eq. (7) represent energy transfer due to conduction, species diffusion, and viscous dissipation, respectively. The subscript $a$ and $s$ represent the air and sludge. The $S_{h}$ is the air enthalpy source term. The $h_{a s}$ is the heat transfer coefficient for the air-sludge interface, $220 \mathrm{~W} \mathrm{~m}^{-2} \mathrm{~K}^{-1}$. The $A_{a s}$ is the interfacial area density which is the ratio of the area of the air/sludge interface and the volume of the porous zone, converted from the specific surface area.

The three conservation equations were jointly solved with the standard $k-\varepsilon$ turbulence model as closure law. According to our previous work, a standard wall function was applied as a macro fluid field of an industrial system (Yu et al., 2014).

\subsubsection{The porous media model}

In the CFD simulation, piles of sludge bio-drying were simulated as porous media, which were modelled by the addition of a momentum source term to the standard fluid flow equations of air (Yan et al., 2008). This momentum sink contributes to the pressure gradient in the porous cell, creating a pressure drop that is proportional to the fluid velocity in the cell. The resistance of the porous zone was calculated by a relative velocity resistance formulation (Eq. (2)). The resistance is composed of two parts: a viscous loss term (Darcy, the first term on the right side of Eq. (9)) and an inertial loss term (the second term on the right side of Eq. (9)).

$\vec{F}=-\left(\sum_{j=1}^{3} D_{j} \mu v_{j}+\sum_{j=1}^{3} C_{j} \frac{1}{2} \rho|v| v_{j}\right)$

The parameters $F$ is the source term for the momentum equation. The parameters $D_{\mathrm{j}}$ and $C_{\mathrm{j}}$ are the viscous resistance coefficients and the inertial resistance coefficients, respectively. Both are equally defined in the $j$ direction vectors because sludge is isotropic. The parameters $v$ and $|v|$ are velocity and magnitude of the velocity, respectively. The parameter $j$ refers to direction vectors for the local characters defined for porous media.

This momentum sink contributes to the pressure gradient in the porous cell, creating a pressure drop that is proportional to the fluid velocity in the cell. With mechanical turning, the pile was assumed homogeneous and isotropic. The viscous loss term was calculated as the homogeneous porous media. The pressure drop is typically proportional to air velocity under the circumstance. Ignoring convective acceleration and diffusion, the viscous loss term in the porous media model then reduces to Darcy's Law (Eq. (10)).

$\Delta \mathrm{p}_{i}=\sum_{j=1}^{3} \mathrm{D}_{\mathrm{j}} \mu_{e} \mathrm{v}_{j} \Delta \mathrm{n}_{i}$

The inertial loss term in the porous media model was calculated as Eq. (11).

$\Delta \mathrm{p}_{i}=\sum_{j=1}^{3} \mathrm{C}_{\mathrm{j}} \Delta \mathrm{n}_{i} \frac{1}{2} \rho_{\mathrm{s}} \mathrm{v}_{\mathrm{j}}|\mathrm{v}|$

where the pressure drop $p$ in each of three $(x, y, z)$ coordinate direction $i$ within the porous region is calculated in the porous cell. The parameter $\mu_{\mathrm{e}}$ is amended air viscosity $(\mu$, $\left.1.7894 \times 10^{-05} \mathrm{~kg} \mathrm{~m}^{-1} \mathrm{~s}^{-1}\right)$. The amend formula is the Einstein Formula $\mu_{\mathrm{e}}=(1+2.5$ FAS $) \mu$, where FAS is defined in Eq. (4). The speed $v$ is superficial velocity porous formulation as the Fluent default. The parameter $n_{i}$ is the thickness of the medium $\left(\Delta n_{i}\right)$ which is the actual thickness of the pile in different sections, according to the geometrical model. The parameter $\rho_{s}$ depends on the moisture contents (Eq. (1)).

\subsubsection{Non-equilibrium thermal model}

There are two major kinds of thermal drying models for solids. The first is thermal sludge drying between $300^{\circ} \mathrm{C}$ and $500{ }^{\circ} \mathrm{C}$ with experimental models. The other one is the aeration for corn barn drying between $10{ }^{\circ} \mathrm{C}$ and $28{ }^{\circ} \mathrm{C}$. The bio-drying differ from these models in three ways: i) Bio-generated heat source, which is rapidly changing and depends on bacteria at four different stages; ii) Multiple heat losses, which heat exchange includes sensible heat exchange (aeration) and latent heat exchange (evaporation) in sync; iii) Complex temperature variation, which is gently rising and sharp drops caused by its specific heat source and loss pathway. Therefore, a non-equilibrium thermal model based on the fundamental heat exchange dynamics was applied.

$$
\begin{aligned}
\frac{\partial}{\partial \mathrm{t}}[\gamma \rho E]+\nabla \cdot(\vec{v}(\rho E+p))= & \nabla \cdot\left[\gamma k_{\text {eff }} \nabla \mathrm{T}-\left(\sum_{i} h_{i} J_{i}\right)+\left(\overline{\bar{\tau}}_{\text {eff }} \cdot \vec{v}\right)\right] \\
& +S_{h}+h_{a s} A_{a s}\left(T_{S}-T_{a}\right)
\end{aligned}
$$

The non-equilibrium thermal model equation (Eq. (12)) was used to simulate the thermal exchange between air and sludge because no equilibrium thermal exchange status was achieved during aeration in the bio-drying. In such a model, a solid sludge zone that is spatially coincident with the porous fluid zone is defined, and this solid zone interacts with the air by adding a source term in the energy equation (Eq. (8)) with regard to heat transfer. The conservation equations for energy are solved separately for the air (Eq. (12)) and solid (Eq. (13)) zones, respectively.

$\frac{\partial}{\partial \mathrm{t}}\left[(1-\gamma) \rho_{s} E_{S}\right]=\nabla \cdot\left[(1-\gamma) k_{s} \nabla \mathrm{T}_{S}\right]+S_{s}+h_{a s} A_{a s}\left(T_{a}-T_{S}\right)$

where subscript $a$ and $s$ represent the air and sludge, respectively. The total solid medium energy of sludge $E_{\mathrm{s}}$ is calculated by Eq. (8). The sludge porosity $\gamma$ is the same as the FAS in the Eq. (4). The term $\mathrm{S}_{\mathrm{S}}$ is the sludge enthalpy source term (Table A.1). The bio-generated heat source terms were $3.2 \mathrm{w} \mathrm{m}^{3}, 0.2 \mathrm{w} \mathrm{m}^{3}, 2.1 \mathrm{w} \mathrm{m}^{3}$, and $0.1 \mathrm{w} \mathrm{m}^{3}$ for four different stages (Zambra et al., 2011), respectively. The heating results were modelled as initial pile temperature $(T)$ in $S_{S}$ for six different sections of each pile. The sludge density $\rho_{S}$ and thermal conductivity $k_{s}$ are calculated with Eqs. (1) and (3), respectively.

\subsubsection{Boundary conditions}

The boundary conditions were a no-slip condition for gas phase on piles walls. The standard wall function was used to model a velocity profile in the vicinity region of the wall. The temperature thermal conditions of $308.15 \mathrm{~K}$ were used for piles walls. The velocity inlet boundary condition was used for modelling the gas inlet from the aerator. The non-uniform gas velocity was specified in accordance with the operational conditions. The pressure outlet boundary condition was applied to the outlet of the reactor (Zhang et al., 2012). The standard initialization was performed to accelerate convergence, initial sections temperatures ( $T$ for $S_{s}$ in Table A.1) were patched as inner temperatures measured with thermocouple (0 min in Fig. 4).

\subsubsection{Mathematical solutions}

The partial differential equations above were solved numerically using the commercial CFD software package Fluent 15.0 (ANSYS Inc., USA). Pile 0,1 and 2 were respectively modelled in three 
corresponding cases of Fluent. The fluent computational domain was the pre-mixed sludge in Section $A$ to $F$ of each pile. The computational domain was discretized with the unstructured hexahedral grid. The Grid interval size $(0.5,2,5,8$ and $20 \mathrm{~mm})$ was implemented in the computational domain. The computational results for different mesh resolutions were examined, and an optimal grid resolution was established on the condition that the finer mesh did not influence the final results by more than $2 \%$ (Zhang et al., 2012). The optimal $2 \mathrm{~mm}$ mesh was thus used in further simulations in this study. Prior to the macroscopic pile temperature simulation, the microscopic simulation of Section B in Pile 0 , was verified with thermograms of the same pile to verify the CFD simulation method and to reveal the mechanism of microscopic temperature evolution. If the CFD simulation method was verified within at the microscopic level, then it could be scaled up to macroscopic level to compare with or verify the probe method, and to reveal further mechanisms of macroscopic temperature evolution.

For all the simulations, the pressure-based solver was used to solve the model equations, and the SIMPLE (Semi-Implicit Method for Pressure Linked Equation) algorithm was used as a pressure-velocity coupling algorithm. The data structure of momentum, energy and pressure were a second order upwind scheme, second order upwind scheme and second order scheme, respectively. The data structure of the turbulence kinetic energy and dissipation rate equations was the first order upwind, in both cases. The gradient scheme of these data was Least Square Cell Based scheme. The time-dependent unsteady calculation was carried out to investigate the temporal variation, and the time discretization was implemented with the first order implicit scheme. Default values of the under-relax factors for all the above mentioned variables were used in the time step iteration process. Fifty internal iterations were carried out to ensure an adequate convergence degree for all the model equations at each time step iteration. If initial convergence difficulties were encountered for a specific time step, the default values were all decreased by $10 \%$ for each attempt until convergence was achieved.

To save computing time, the following time-stepping strategy was compared: 200 steps at $0.005 \mathrm{~s}, 400$ steps at $0.01 \mathrm{~s}, 350$ steps at $0.02 \mathrm{~s}, 200$ steps at $0.05 \mathrm{~s}, 200$ steps at $0.1 \mathrm{~s}, 400$ steps at $0.2 \mathrm{~s}$, and 2540 steps at $0.3 \mathrm{~s}$. The time step was finally optimized as $0.3 \mathrm{~s}$. A typical aeration calculation time was over $900 \mathrm{~s}$. The first $120 \mathrm{~s}$ was to ensure that the flow reached a steady or pseudo-steady state, and the time averaged values of flow variables for another $60 \mathrm{~s}$ were taken for evaluation. After the flow was evaluated as stabilized, temperature evolutions were investigated in the next $720 \mathrm{~s}$. The calculation was run on a Lenovo workstation (D20, $2 \times$ Intel Xeon E5630, 32 GB RAM). Typical physical computing time was approximately $60 \mathrm{~h}$. Residual convergence criteria for all variables were set as $1 \times 10^{-4}$.

\section{Results}

\subsection{Pile temperature at different depths measured by the thermocouple}

Fig. 2 shows spatio-temporal pile temperature variation at pile depth of $0.5 \mathrm{~m}$ and $1.5 \mathrm{~m}$, and bio-drying performance of three piles with three aeration strategies. The pile temperature variations went through four different stages including temperature increasing stage, thermophilic stage, the second temperature increasing stage, and cooling stage. For both depths, the Pile 0,1 and 2 reached the highest pile temperature in 2 days, 1 day and 1 day of temperature increasing stage, respectively. And then the Pile 0,1 and 2 maintained over $50^{\circ} \mathrm{C}$ for 12 days, 8 days and 4 days in the thermophilic stage and the second temperature increasing stage, respectively. During the rise and fall of pile temperature at the surface and interior, the Pile 0,1 and 2 achieved the highest rate of $+5.3{ }^{\circ} \mathrm{C} \cdot \mathrm{d}^{-1}$ and $-27{ }^{\circ} \mathrm{C} \cdot \mathrm{d}^{-1}, \quad+29{ }^{\circ} \mathrm{C} \cdot \mathrm{d}^{-1}$ and $-18{ }^{\circ} \mathrm{C} \cdot \mathrm{d}^{-1},+18{ }^{\circ} \mathrm{C} \cdot \mathrm{d}^{-1}$ and $-18{ }^{\circ} \mathrm{C} \cdot \mathrm{d}^{-1}$, respectively. The time interval over which Pile 1 achieved the highest pile temperature and maintained it at $>50{ }^{\circ} \mathrm{C}$ was 1 day and 8 days, respectively, and the corresponding pile temperature rise and fall rates were $29^{\circ} \mathrm{C} \cdot \mathrm{d}^{-1}$ and $-18{ }^{\circ} \mathrm{C} \cdot \mathrm{d}^{-1}$. These results showed that the aeration strategy for Pile 1 provided a sufficient oxygen to speed up the temperature rise in the pile. Meanwhile, the aeration strategy also slowed down the temperature decrease as expected to $9{ }^{\circ} \mathrm{C} \cdot \mathrm{d}^{-1}$ (Ramirez et al., 2012). The time interval over which Pile 2 achieved the highest pile temperature and maintained $>50^{\circ} \mathrm{C}$ was 1 day and 4 days, respectively. The corresponding temperature rise and fall rates were $18{ }^{\circ} \mathrm{C} \cdot \mathrm{d}^{-1}$ and $-18^{\circ} \mathrm{C} \cdot \mathrm{d}^{-1}$, respectively. These results showed that the initial thermophilic stage of Pile 2 was successfully prolonged with improved aeration and turning strategy.

To further discuss the effects of aeration on temperature variation, Pile 1 and Pile 2 were compared with Pile 0 (control group). The aeration strategy of Pile 2 was efficient in mass reduction (Fig. A.3), considering that SRT decreased from 21 days (Pile 0,1 ) to 14 days (Pile 2 ), and aeration decreased $20 \%$ (Table 1 ) compare with Pile 0. Compared with the control group, Pile 1 had more initial aeration, followed by decreasing aeration. The optimized strategy led to lower initial temperature, but followed with a warmer and longer second thermophilic stage. The highest interior temperature $\left(75^{\circ} \mathrm{C}\right)$ was achieved in the second temperature-increasing stage of Pile 1, with less aeration in its Section C. Significantly more MC was also removed (6.5\%) at the same time. Pile 2 operation was designed with slightly decreased middle stage aeration and doubled turning frequency. The peak temperature was lower in Pile 2, and decreased more rapidly than in the control group Pile 0 . More temperature comparisons between them and their effects on MC removal are discussed further in the Supplementary information (Fig. A.3). In all three aerations strategies, the difference between the surface $(0.5 \mathrm{~m})$ and interior $(1.5 \mathrm{~m})$ temperatures was more significant in the second temperature-increasing stage, for which further investigation of the mechanism is needed.

\subsection{Pile temperature on surface measured by the Infrared Thermal Imager (ITI)}

Pile temperature used to be determined by a thermometer with a temperature probe. These methods were accurate but timeconsuming because limited by the heat conduction speed of the probe (Ramirez et al., 2012). For example, it is scarcely possible to determine the pile temperature spatial variation within a 4 min aeration in Section A of Pile 0 , as the temperature balance between temperature probe and piles may require $1-3$ min or more (Rainisalo et al., 2011). The heat conduction speed also limits the temperature probe as a spatio-temporal averaging method. Infrared thermometry provides a speedy method within several seconds, to learn the spatial temperature distribution of objects surface (Marins et al., 2014). The infrared thermal imager is an integration of the matrix of an infrared sensor, which allows speedy determination of regional temperature at the pile surface. Therefore, thermograms snapshot provides an accurate way to determine the temporal temperature changes within the imager lens coverage, during aeration for sludge bio-drying.

The first row of Fig. 3 is thermogram snapshots in the marked surface region of Section B, Pile 1 (Fig. A.2). The thermograms were captured every 2.0 min during the 6 min' aeration; so the series of thermograms represented the temporal temperature variation at the pile surface during the given aeration strategy. Before aeration 


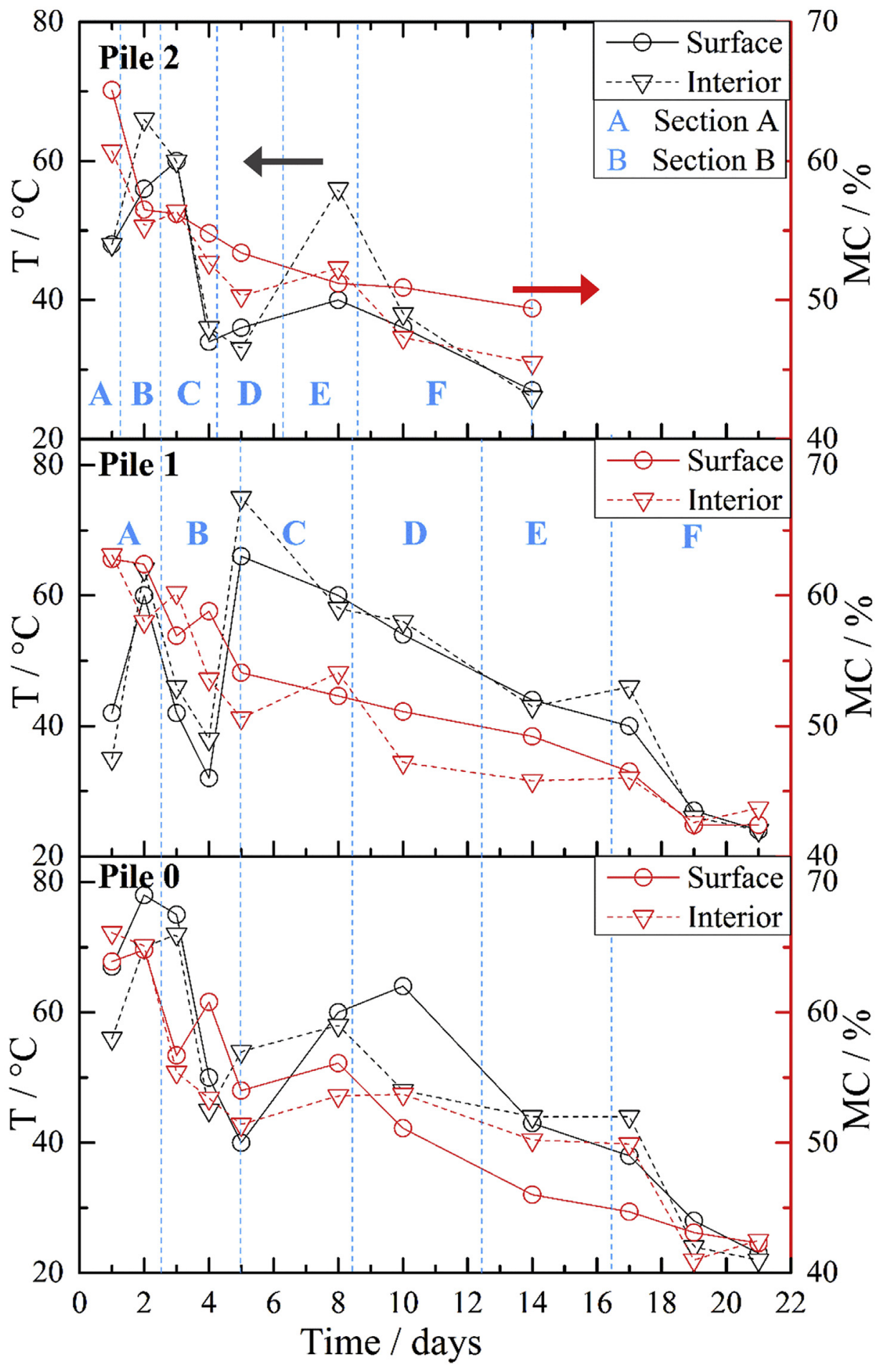

Fig. 2. Spatial temperature and moisture removal variation under different aeration strategies.

began, there were many hotspots $\left(69.8-72.5^{\circ} \mathrm{C}\right)$ spread all over the region, as well as spots with lower pile temperature in a few gaps between sludge bulk. After aeration started, the surface pile temperature rapidly increased to $70.6{ }^{\circ} \mathrm{C}$ in most of the region. The temperature increase to $62.9^{\circ} \mathrm{C}$ was delayed in the right bottom corner. Meanwhile the surface pile temperature was decreased in the initially increased region. With continued aeration, the surface pile temperature was further decreased to $39.0-45.6{ }^{\circ} \mathrm{C}$ in the region. Results showed that the surface pile temperatures were non-uniform, and changed rapidly during aeration. Because the pile temperature is essential to bio-drying, these non-uniform evolutions of pile temperature would lead to heterogeneous bio-drying products (Rainisalo et al., 2011).

With thermocouple (Fig. 2) and IRI results (Fig. 3 Row 1), another important spatial temperature variation was revealed, which is related to the heat and moisture exchange between 

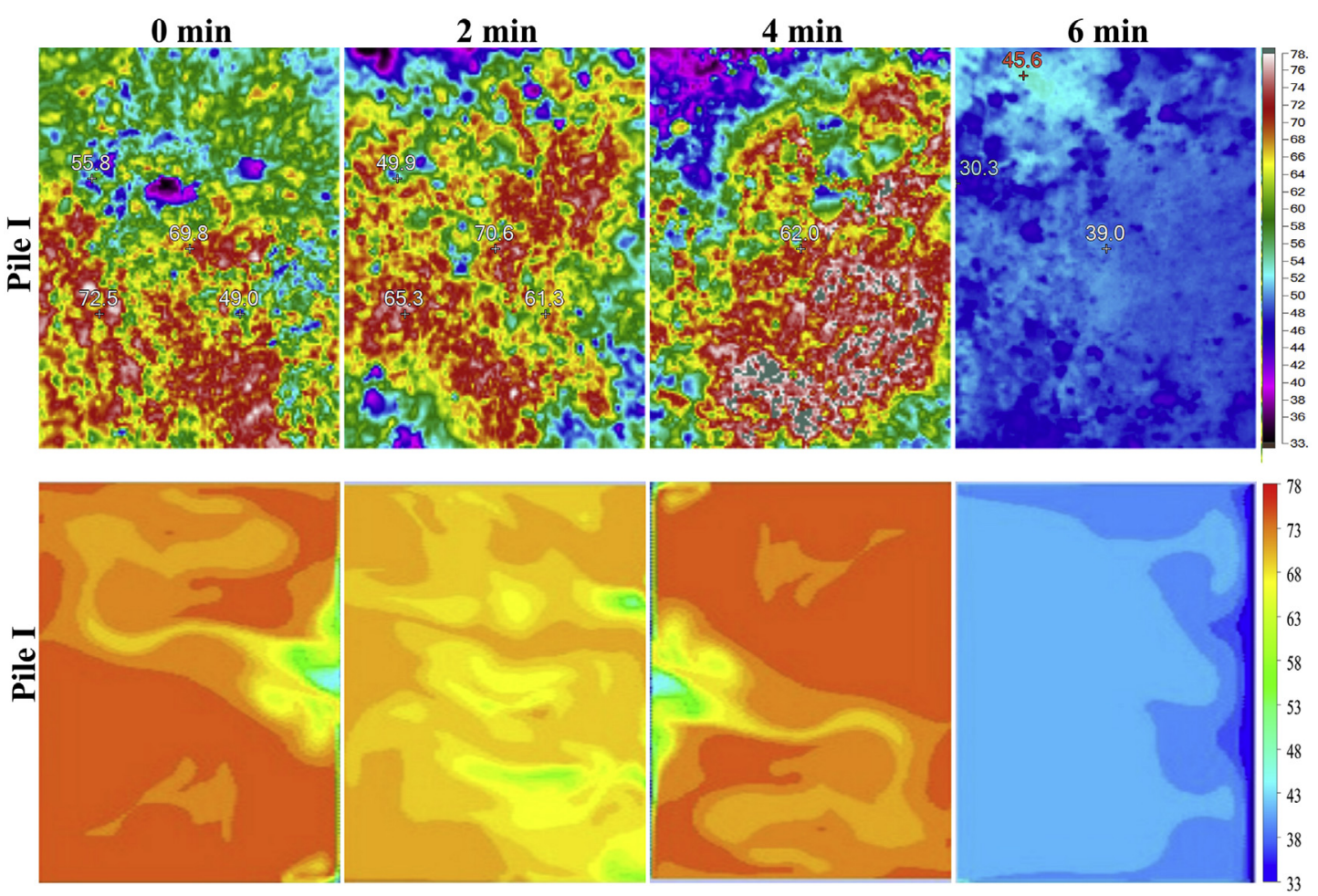

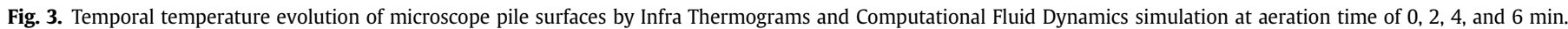

interior and surface of the pile when the MC of the pile moved from the interior to the surface. Generally, the surface pile temperature was lower than the interior due to heat loss. However, the surface pile temperature was higher than the interior in the first two sections of Pile 0 due to condensation in the surface, leading to surface MC increased by $0.9 \%$ and $2.1 \%$, respectively (Fig. 2). Therefore, the surface MC of the pile gradually accumulated to become higher than that in the interior of Section B and C, until the second temperature increasing stage. The surface pile temperature rapidly increased in the second temperatureincreasing stage (Fig. 3 Row 1), which led to an immediate decrease of surface MC between days $5-8$ in Pile 0 (Fig. 2). Another interesting water exchange occurred between the interior and surface in Section A, B and C of Pile 1 (Days 0-8, Fig. 2), where interior and surface MC declined alternately. However, the interior pile temperatures were slightly higher than the surface pile temperature (Fig. 2), which indicated that a delicate balance was maintained between evaporation and condensation by aeration. The MC difference between the surface and interior pile was obvious in Section F of Pile 2 (Fig. 2) despite enhanced aeration (Table 1). This difference was probably caused by the higher interior pile temperature $56{ }^{\circ} \mathrm{C}$ in the second temperature increasing stage (Fig. 2). Because the surface temperature was similar to the interior temperature at last 3 days in Section F of Pile 2 , the surface and interior MCs were decreased an additional $4 \%$ by excess aeration (Fig. 2). The results showed that excess aeration failed to narrow the MC difference without temperature difference, due to lack of synchronization in the heat and MC exchange. Although surface and interior MC difference are essential for homogeneous bio-drying processes and products, it remains a great challenge to monitor the pile temperature matrix due to probe installation difficulties within the huge pile and to issues related to mechanical agitation.

\subsection{Pile temperature by Computational Fluid Dynamics (CFD)}

The CFD results of pile temperature evolution during aeration could provide a full 3-d temperature distribution of where aeration affects temperature evolution more significantly. The second row of Fig. 3 shows the CFD simulation results in the same position and moment as on the first row of Fig. 3. These CFD simulation results clearly show that the hotspot of pile temperature migrates from lower left to upper right, similar to the thermodynamic pattern in the thermograms, regarding hotspot migration. The peak pile temperature reached $70.6-72.5^{\circ} \mathrm{C}$ in the major parts of the region, especially the lower left corner in the CFD simulation, which was validated with the IRI results (Zambra and Moraga, 2013). The difference between CFD simulation and IRI thermogram were summarized in a quantitative way as Table 2 . These results showed that CFD could simulate the evolution of the pile temperatures

Table 2

Difference between CFD simulation and IRI thermogram.

\begin{tabular}{|c|c|c|c|c|c|c|c|c|c|c|c|c|}
\hline \multirow[t]{2}{*}{ Location } & \multicolumn{3}{|c|}{$0 \mathrm{~min}$} & \multicolumn{3}{|l|}{$2 \min$} & \multicolumn{3}{|l|}{$4 \mathrm{~min}$} & \multicolumn{3}{|l|}{$6 \mathrm{~min}$} \\
\hline & left & Center & right & left & Center & right & $\overline{\text { left }}$ & Center & $\overline{\text { right }}$ & $\overline{\text { left }}$ & Center & right \\
\hline Top & $1.4 \%$ & $4.6 \%$ & $9.4 \%$ & $6.0 \%$ & $1.4 \%$ & $1.4 \%$ & $78.6 \%$ & $13.8 \%$ & $11.9 \%$ & $-2.4 \%$ & $-8.7 \%$ & $-6.7 \%$ \\
\hline Middle & $2.8 \%$ & $-1.4 \%$ & $-1.5 \%$ & $-1.4 \%$ & $-4.2 \%$ & $-1.4 \%$ & $-2.9 \%$ & $4.4 \%$ & $2.9 \%$ & $0.3 \%$ & $-7.1 \%$ & $-6.5 \%$ \\
\hline low & $0.7 \%$ & $-1.4 \%$ & $4.3 \%$ & $1.4 \%$ & $-4.2 \%$ & $-2.9 \%$ & $7.4 \%$ & $1.4 \%$ & $2.9 \%$ & $5.4 \%$ & $-2.5 \%$ & $-0.5 \%$ \\
\hline
\end{tabular}


during aeration.

As an accurate simulation method, CFD helps provide fundamental understanding of the mechanism by which aeration affects bio-drying. The management of heat and MC removal remains a great challenge for optimizing aeration strategy in the bio-drying process. This is because there is conflicting evidence for the superiority of low or high aeration rates. For example, it is reported that bio-drying could benefit from a lower aeration rate by maintaining higher pile temperature (Huilinir and Villegas, 2015). However, benefits for bio-drying from a higher aeration rate were also reported in the form of quick MC removal. The total bio-drying period was able to be decreased from 21 days to 14 days with a higher aeration rate in the last cooling stage of Pile 2. CFD simulation showed that the mechanism of non-uniform surface pile temperature evolution was mainly affected by heat and MC transformation, which mainly occurred in free air spaces (FAS) coupled with air exchanges during aeration. The surface pile temperature was initially increased due to enhanced convection of heat by the forced air. Prior to aeration, there were many small hotspots in the first thermogram as the bio-generated heat accumulated in the interior of the sludge granules and piles (Fig. 3). This interior accumulated heat was convection rather than by conduction to the surface of granules and piles by air. For this reason, the heat convection was greatly affected by the FAS of the granules and piles. These FAS differences lead to the lag in the pile temperature increase in the lower right corner of the third thermogram (Fig. 3).

These microscopic mechanisms of that how FAS affects aeration had also been revealed by CFD previously. An area of the pile with lower FAS, has a higher temperature due to the accumulation of bio-generated heat. High-temperature parts of the pile also have higher local pressure, therefore less aeration. In contrast, areas with higher FAS have lower temperature due to less accumulation of biogenerated heat. The low-temperature parts of the pile also have lower local pressure, therefore more aeration. These convection characteristics enhanced the microscopic non-uniformity.

\subsection{Spatio-temporal evolution of pile temperature during aeration by CFD simulation}

Pile thermal processes on the surface during aeration were preciously captured with thermograms, and vividly depicted with CFD simulation, in the full-scale bio-drying plant. The spatial pile temperature evolution, and surface pile temperature spatiotemporal evolution have already been described above. Therefore, macroscopic interior temperature spatio-temporal evolution will be discussed in this section. For six different sections of the investigated tunnel, the pile temperature evolution during forced aeration is shown in Fig. 4 by verified CFD simulation. The forced aeration and turning procedure were carried out according to Table 1 , and turning was done prior to the aeration for each section's homogeneous.

CFD results reveal patterns similar to those from the three aeration strategies for MC and heat migration from one section to another. With the shortest aeration of $4 \mathrm{~min}$ in Section A (Table 1), Pile 0 rapidly achieved the peak interior temperature in the thermophilic stage (Fig. A.3b). The pile temperature drop was fading gradually in this stage, slower than that in Section B especially in the last period. Section $C$ also experienced rapid heat lost, as well as

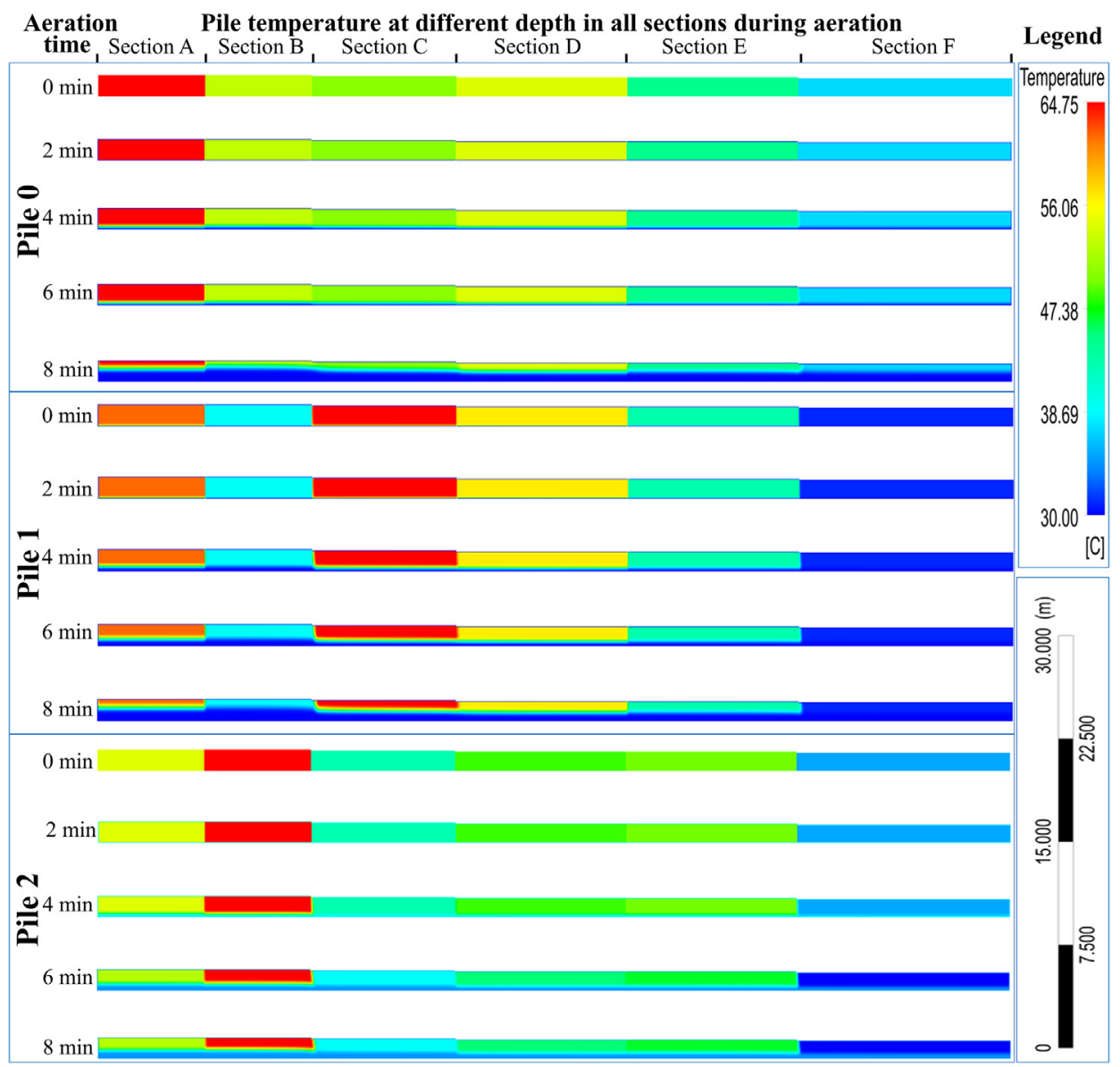

Fig. 4. Spatio-temporal temperature evolution of macroscopic pile interior by Computational Fluid Dynamics simulation for Pile 0,1 and 2. 
prolonged aeration time. These led to a lag in the second pile temperature increasing stage, which appeared in Section D of Pile 0. These delays also promoted the interior pile temperature of Section $\mathrm{E}$ as well as Section F, which remained $>35^{\circ} \mathrm{C}$. Different from Pile 0 , the Pile 1 went through a pile temperature increasing stage in Section A, where the pile temperature drop was more gradual and slightly more rapid than for the control Pile 0 . The pile temperature drop in Section B of Pile 1 was the section with the most rapid drop, which was in accordance with the pile temperature valley in Fig. 2. Then the pile temperature drop during aeration was much slower in Section C, leading to the pile temperature peak in Pile 1 in Section C. The last three sections of Pile 1 exhibited a similar drop in pile temperature as in Section C, which resulted in a little higher MC in the bio-drying products. Pile 2 maintained similar pile temperature drop in all sections, which may have been caused by the doubled turning frequency. The enhanced mixing made the pile more uniform. These similar trends between MC removal and pile temperature drop indicated the synchronous migration of MC and heat in these piles.

\subsection{Mechanism of the pile temperature valley}

Aeration in bio-drying assumes three major roles: supplying oxygen, transporting heat and removing MC. The five pile sections need different aeration roles as they undergo four major stages (Zhao et al., 2010). However, these three roles of aeration cannot be isolated by section needs, so the pile temperature will drop sharply if air demand for MC removal is far more than taking out heat. Such phenomena more likely happen between the thermophilic stage and the second temperature rising stage, when the biogenerated heat is insufficient in the period during which the microbial community structure is shifting (Zhang et al., 2015). The combined effects of thermodynamics and microbial community structure lead to a high probability of pile temperature drop, which looks like a temperature valley. The pile temperature valley, associated with more thermal lost and less MC removal was generally observed between two thermophilic stages, i.e. Pile I.

Water vapour or air moisture is determined by the relative humidity which is mainly affected by air temperature. If the relative humidity of the air is $>100 \%$, the water vapour will be supersaturated. This would condense and prevent evaporation of moisture from the pile. With the same relative humidity, higher air temperature liberates much more moisture which enhances pile moisture evaporation (Cai et al., 2012). Therefore, similar pile could lose different moisture due to different pile temperatures. Furthermore, decreased temperature from the interior to the surface of the pile will lead to supersaturation of the air. The decreased temperature cools the supersaturated air, which makes moisture migrate from pile interior to the surface, as happened in Pile 2.

The relative humidity that determines the moisture transport could be calculated using the Wexler formula, Goff-Gratch formula and other experience models, i.e. Magnus formula. The Wexler formula is shown as Eq. (14) (ASTM, 2015).

$\ln E=\sum_{i=0}^{3} C_{i} T^{i-1}+C_{4} \ln T$

where, constants $C_{0}=-6.0436117 \times 10^{3}, C_{1}=1.89318833 \times 10^{1}$, $C_{2}=-2.8238594 \times 10^{-2}, \quad C_{3}=1.7241129 \times 10^{-5}$, and $C_{4}=2.858487$; $\mathrm{T}$ is the air temperature, $\mathrm{K}$; and $\mathrm{E}$ is the saturated vapour pressure $(\mathrm{Pa})$ of the wet hot air. Considering the $\mathrm{MC}$ range (40\%-60\%) of the sludge bio-drying, the evaporation and condensation recycling happening between the surface and interior of the pile can be represented as the psychometric chart (ASTM, 2012). As the surface pile temperature was lower than the interior, the air from the interior of piles can be supersaturated when it reaches the pile surface. When the surface pile temperature decreased to below the dew-point temperature, the supersaturated vapour could condense on the pile surface (ASTM, 2012). The dew-point temperature can be determined by the evaporation and condensation recycling, as we all known in the psychometric chart (ASTM, 2012). These supersaturated vapors from the interior were condensed when they were released from the pile, leading to interior pile moisture transported to the pile surface, along with condensation heat, leading to a surface temperature higher than the interior temperature, for example, as in the second temperature increasing stage of Pile 0.

\section{Discussion}

The merit of effluent saturates vapour is that most of the biogenerated heat is used for evaporation, rather than heat exhausted on heating air. Therefore, the saturated vapour brought less heat while removing a similar amount of moisture from the piles (Haug, 1993). For example, Pile 0 and Pile 2, which had higher thermal stage temperatures, were more efficient in removal of MC than was Pile 1 . Because excessive aeration meant that the air was no longer saturated in the thermodynamic region of Pile 1 , less moisture and more heat was released from the pile, which led to a significant valley in the pile temperature before the second temperature increase stage. The evaporation latent heat $\left(2258 \mathrm{~kJ} \mathrm{~kg}^{-1}\right.$, $100{ }^{\circ} \mathrm{C}, 0.1 \mathrm{mPa}$ ) of water is much more significantly than specific heat $\left(4.2 \mathrm{~kJ} \mathrm{~kg}^{-1} \cdot{ }^{\circ} \mathrm{C}^{-1}, 0-100{ }^{\circ} \mathrm{C}, 0.1 \mathrm{mPa}\right)$, which means that $\Delta \mathrm{T}=5.38{ }^{\circ} \mathrm{C}$ is needed for per MC removal. The inferred $\Delta \mathrm{T}$ value was a theoretical calculation of the latent heat of $1 \%$ moisture removed for $99 \%$ of pile substrate with similar specific heat, despite $40-80 \%$ MC. The tested ratio $\Delta T$ per MC removal in the three piles reported, was calculated as the average specific ratio of the pile temperature drop per MC removal in all samples (Eq. (15)), where the tested $r_{t}=5.17 \pm 4.56{ }^{\circ} \mathrm{C}$ meets the theoretically inferred $\Delta T$ well.

$\mathrm{r}_{t}=\frac{\Delta T}{\Delta M C}=\frac{\left|T_{i+1}-T_{i}\right|}{\left|M C_{i+1}-M C_{i}\right|}$

The difference between the test $r_{t}$ and theoretical $r_{t}=5.38{ }^{\circ} \mathrm{C} \mathrm{MC}^{-1}$, and can be used to evaluate the efficiency of the aeration flow rate. Higher outlet air temperature brings more sensible heat, due to bring more MC. Therefore, the $\Delta \mathrm{T}$ will be higher in the thermophilic stage. However, the test $r_{t}$ is higher also due to heat transfer caused by excess aeration (Fig. 5b). The practical value over the theoretical value represents excess air over the amount of MC to be removed. The latent heat of the gas to liquid phase transformation also dominated the moisture and heat exchange among the interior, surface and atmosphere. The quick loss of latent heat strengthens heat exchange, coupled with the shift in thermophilic bacteria, both increase the probability of a temperature valley between the thermophilic stage and second temperature increasing stage. Prolonged aeration enhanced MC removal more in the cooling stage than in the other two stages. In the cooling stage, as pile temperature decreased, excessive air must also have been exhausted to remove MC because the temperature limited the absolute humidity. And the MC removal under different aeration strategies depends on the relative humidity of the outlet air in the thermodynamic region. Because the air non-saturated with water vapour takes away more heat than MC in the two stages, the pile temperature was lower and thus the MC removal was less efficient. Therefore, the saturate outlet air was advised as 


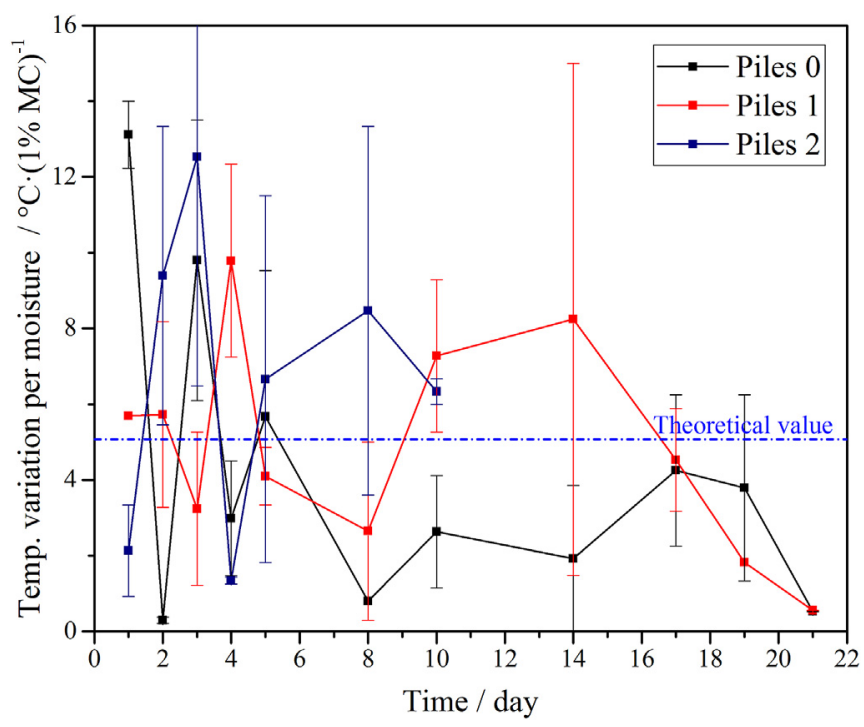

Fig. 5. Average temperature drop per $1 \%$ moisture removed.

the optimizing aeration strategy for bio-drying, especially in the first thermodynamic region.

The total energy output involves three parts that include temperature variation of the pile and air, and latent heat of MC removal during the aeration. The total energy output can be calculated using the sensible and latent heat transport path shown in Eq. (16).

$E_{T}=\int_{T_{\text {in }}}^{T_{\text {out }}} \mathrm{c}_{p} \rho_{s} \mathrm{v}_{\mathrm{s}} d T+\int_{T_{\text {in }}}^{T_{\text {out }}} \mathrm{c}_{j} \rho_{j} \mathrm{v}_{\mathrm{j}} d T+r\left(M C_{\text {in }}-M C_{\text {out }}\right)$

where subscript $s$ and $j$ refers to pile and air, $c_{\mathrm{p}}$ is the specific heat capacity of the pile, and $r$ is the latent heat of MC. The typical value of $c_{\mathrm{p}}, c_{\mathrm{j}}$ and $r$ is $2.8 \mathrm{~kJ} \mathrm{~kg}^{-1} \mathrm{~K}^{-1}, 1.1 \mathrm{~kJ} \mathrm{~kg}^{-1} \mathrm{~K}^{-1}$ and $2258 \mathrm{~kJ} \mathrm{~kg}^{-1}$, respectively, for Pile 0 in the thermophilic stage (ASTM, 2015; Haug, 1993). The latent heat is much higher than the specific heat capacity, which accounts for $73-85 \%$ of total heat output various from pile temperature. Therefore, the spatio-temporal evolution of the interior temperature can be manipulated through moisture management due to its massive latent heat, especially if the outlet air temperature reaches supersaturated or dew-point temperature. For example, heat loss was more rapid in Pile 1 than in Pile 0 , but moisture removal was similar. Previous research showed that heat production was insensitive to air-flow except at the lowest air-flow rate (Zhao et al., 2011). Therefore, the pile temperature evolution was more sensitive to heat loss during aeration which involved sensitive heat air exchange and the latent heat in evaporating moisture. For reference, evaporation of water resulted in loss of 52\% and $42 \%$ of bio-generated energy as $520 \mathrm{MJ}$ and $421 \mathrm{MJ}$, respectively, for air-flow rates of $0.0042-0.012 \mathrm{~m}^{3} \mathrm{~h}^{-1} \mathrm{~kg}^{-1} \mathrm{VS}$ and $0.0234-0.0312 \mathrm{~m}^{3} \mathrm{~h}^{-1} \mathrm{~kg}^{-1}$ VS in a 30 days' manure composting (Ahn et al., 2007). The heat loss caused by water evaporation accounted for a large proportion of the energy use in bio-drying, which is dedicated to water evaporation. This mechanism also explains why double aeration achieved similar MC removal. Pile 1 and Pile 0 achieved similar MC reduction of $54.0 \%$ and $54.1 \%$ after the thermophilic stage, despite that the aeration time of Pile 1 was double that of Pile 0 in Section A and B. Therefore, evaporation of moisture is insensitive to excess aeration in the thermophilic stage.

In a word, heat loss is more sensitive to moisture evaporation than to excess aeration in the thermophilic stage. This makes relative humidity a more sensitive controlled variable than is thermocouple temperature. Many control strategies were available to regulate air supply to the process. These range from simple manual control systems to more sophisticated feedback control loops using temperature, oxygen or carbon dioxide as the controlled variables and air supply as the manipulated variable (Winkler et al., 2013; Zhang et al., 2008). Therefore, thermodynamic automation strategies should be controlled by maintaining the outlet air in water saturate condition, and should operate over the full range from minimum to peak air flow conditions. Equipped with this novel aeration automation strategy, the pile temperature valley will be efficiently narrow, enhancing moisture removal, and with the lowest temperature drop.

\section{Conclusions}

The effects of aeration on the pile matrix temperature were measured by infra thermogram image and modelled using CFD in this study. Conclusions are as follows:

1. Aeration impacts the pile matrix temperature primarily by exchanging MC and latent heat simultaneously between the interior and surface of the pile. CFD results revealed that the non-uniform evolution of microscopic temperature was primarily affected by the FAS.

2. The exchange rate for the pile matrix temperatures was $\Delta \mathrm{T}=5.38{ }^{\circ} \mathrm{C}$ per unit of $\mathrm{MC}$ removed for both evaporation removal and condensation acquisition during aeration theoretically. Practically, the $\Delta \mathrm{T}=5.17 \pm 4.56^{\circ} \mathrm{C}$ was because that high temperature air has high MC holding capacity and accepts more sensible heat.

3. The improved aeration strategy based on IRI and CFD allows for a sludge bio-drying operation with both shorter period from 21 days to 14 days and similar 40\% MC in the bio-drying product.

\section{Acknowledgments}

This work was funded by the Major Science and Technology Program for Water Pollution Control and Treatment of China (2012ZX07202-005) and the National Natural Science Foundation of China (21377151).

\section{Appendix A. Supplementary data}

Supplementary data related to this article can be found at http:// dx.doi.org/10.1016/j.watres.2017.06.003.

\section{References}

Ahn, H.K., Richard, T.L., Choi, H.L., 2007. Mass and thermal balance during composting of a poultry manure - Wood shavings mixture at different aeration rates. Process Biochem. 42 (2), 215-223.

ASTM, 2012. Standard Test Method of Measuring Humidity with Cooled-surface Condensation (Dew-Point) Hygrometer. American Society for Testing and Materials.

ASTM, 2015. Standard Test Method for Measuring Humidity with a Psychrometer. American Society for Testing and Materials.

Bendjebbas, H., Abdellah-ElHadj, A., Abbas, M., 2016. Full-scale, wind tunnel and CFD analysis methods of wind loads on heliostats: a review. Renew. Sustain. Energy Rev. 54, 452-472.

Cai, L., Gao, D., Chen, T.B., Liu, H.T., Zheng, G.D., Yang, Q.W., 2012. Moisture variation associated with water input and evaporation during sewage sludge bio-drying. Bioresour. Technol. 117, 13-19.

Cai, L., Chen, T.B., Gao, D., Zheng, G.D., Liu, H.T., Pan, T.H., 2013. Influence of forced air volume on water evaporation during sewage sludge bio-drying. Water Res. 47 (13), 4767-4773.

Cai, L., Chen, T.B., Gao, D., Yu, J., 2016. Bacterial communities and their association with the bio-drying of sewage sludge. Water Res. 90, 44-51.

Frei, K.M., Cameron, D., Stuart, P.R., 2004. Novel drying process using forced aeration through a porous biomass matrix. Dry. Technol. 22 (5), 1191-1215. 
General Office of the State Council, 2012. Sewage Treatment and Recycling Facility Construction Plan (2011-2015). General Office of the State Council, Beijing.

Guardo, A., Coussirat, M., Larrayoz, M.A., Recasens, F., Egusquiza, E., 2004. CFD flow and heat transfer in nonregular packings for fixed bed equipment design. Ind. Eng. Chem. Res. 43 (22), 7049-7056.

Haug, R.T., 1993. The Practical Handbook of Compost Engineering. Lewis Publishers, California, USA.

He, P.J., Zhao, L., Zheng, W., Wu, D., Shao, L.M., 2013. Energy balance of a biodrying process for organic Wastes of high moisture content: a review. Dry. Technol. 31 (2), 132-145.

Huang, Y.W., 2015. Feat and Mass Transfer Characteristics of Manicipal Sludge During Hot Air Convective Drying. Beijing Jiaotong University.

Huilinir, C., Villegas, M., 2014. Biodrying of pulp and paper secondary sludge: kinetics of volatile solids biodegradation. Bioresour. Technol. 157, 206-213.

Huilinir, C., Villegas, M., 2015. Simultaneous effect of initial moisture content and airflow rate on biodrying of sewage sludge. Water Res. 82, 118-128.

Marins, J.C., Fernandes, A.A., Cano, S.P., Moreira, D.G., da Silva, F.S., Costa, C.M., Fernandez-Cuevas, I., Sillero-Quintana, M., 2014. Thermal body patterns for healthy Brazilian adults (male and female). J. Therm. Biol. 42, 1-8.

Norton, T., Sun, D.W., Grant, J., Fallon, R., Dodd, V., 2007. Applications of computational fluid dynamics (CFD) in the modelling and design of ventilation systems in the agricultural industry: a review. Bioresour. Technol. 98 (12), 2386-2414.

Rainisalo, A., Romantschuk, M., Kontro, M.H., 2011. Evolution of clostridia and streptomycetes in full-scale composting facilities and pilot drums equipped with on-line temperature monitoring and aeration. Bioresour. Technol. 102 (17), 7975-7983.

Ramirez, A.A., Godbout, S., Leveillee, F., Zegan, D., Larouche, J.P., 2012. Effect of temperature and air flow rate on carbon and nitrogen compounds changes during the biodrying of swine manure in order to produce combustible biomasses. J. Chem. Technol. Biotechnol. 87 (6), 831-836.

Shen, Y., Ren, L., Li, G., Chen, T., Guo, R., 2011. Influence of aeration on CH4, N2O and $\mathrm{NH} 3$ emissions during aerobic composting of a chicken manure and high C/N waste mixture. Waste Manag. 31 (1), 33-38.

State Council of China, 2015. The Action Plan for Water Pollution Prevention and Control.

Tom, A.P., Haridas, A., Pawels, R., 2016. Biodrying process efficiency:- significance of reactor matrix height. 1st global colloquium on recent advancements and effectual researches in engineering. Sci. Technol. Raerest. 25, 130-137.

US Composting Council, 2002. Test Methods for the Examination of Composting and Compost. US Composting Council, Bethesda, MD.

Villegas, M., Huilinir, C., 2014. Biodrying of sewage sludge: kinetics of volatile solids degradation under different initial moisture contents and air-flow rates. Bioresour. Technol. 174, 33-41.

Wang, Y.C., Zheng, J., Fang, J.Y., Hu, C.X., Wu, Y.P., Li, J.X., 2015. Experimental study on thermal conductivity of sludge in drying process. Acta Energiae Solaris Sin. 36 (3), 703-707 (in Chinese).

Wei, Y.S., Li, C.Q., Fan, Y., Wang, M., Jia, Z., 2001. Effect on sewage sludge composting with different aeration modes. Environ. Sci. 22 (3), 54-59.

Winkler, M.K., Bennenbroek, M.H., Horstink, F.H., van Loosdrecht, M.C., van de Pol, G.J., 2013. The biodrying concept: an innovative technology creating energy from sewage sludge. Bioresour. Technol. 147, 124-129.

Yan, W.W., Liu, Y., Xu, Y.S., Yang, X.L., 2008. Numerical simulation of air flow through a biofilter with heterogeneous porous media. Bioresour. Technol. 99 (7), 2156-2161.

Yang, B., Zhang, L., Jahng, D., 2014. Importance of initial moisture content and bulking agent for biodrying sewage sludge. Dry. Technol. 32 (2), 135-144.

Yu, D.W., Wei, Y.S., Fan, Y.B., Ding, W., 2014. Flat-sheet membrane bioreactors computational fluid dynamics multiphase flow turbulence model experimental validation. CIESC J. 65 (z1), 377-385 (in Chinese).

Zambra, C.E., Moraga, N.O., 2013. Heat and mass transfer in landfills: simulation of the pile self-heating and of the soil contamination. Int. J. Heat Mass Transf. 66, 324-333.

Zambra, C.E., Moraga, N.O., Escudey, M., 2011. Heat and mass transfer in unsaturated porous media: moisture effects in compost piles self-heating. Int. J. Heat Mass Transf. 54 (13-14), 2801-2810.

Zhan, W.F., Chen, Y.H., Voogt, J.A., Zhou, J., Wang, J.F., Ma, W., Liu, W.Y., 2012 Assessment of thermal anisotropy on remote estimation of urban thermal inertia. Remote Sens. Environ. 123, 12-24.

Zhang, D.Q., He, P.J., Jin, T.F., Shao, L.M., 2008. Bio-drying of municipal solid waste with high water content by aeration procedures regulation and inoculation Bioresour. Technol. 99 (18), 8796-8802.

Zhang, T., Wei, C., Feng, C., Zhu, J., 2012. A novel airlift reactor enhanced by funnel internals and hydrodynamics prediction by the CFD method. Bioresour. Technol. $104,600-607$.

Zhang J.Y, Cai, X, Oi, L, Shao, C., Lin, Y, Zhang, J., Zhang Y Shen, P., Wei, Y, 2015. Effects of aeration strategy on the evolution of dissolved organic matter (DOM) and microbial community structure during sludge bio-drying. Appl. Microbiol Biotechnol. 99 (17), 7321-7331.

Zhao, L., Gu, W.M., He, P.J., Shao, L.M., 2010. Effect of air-flow rate and turning frequency on bio-drying of dewatered sludge. Water Res. 44 (20), 6144-6152.

Zhao, L., Gu, W.M., He, P.J., Shao, L.M., 2011. Biodegradation potential of bulking agents used in sludge bio-drying and their contribution to bio-generated heat. Water Res. 45 (6), 2322-2330. 